\title{
Sustainability through Intelligence in Buildings
}

\author{
Nikoleta Parthenopoulou, Mrs, * \\ * PhD Candidate in Architectural Design and Architectural Technology \\ (School of Architecture, Faculty of Engineering, Aristotle University of Thessaloniki, University Campus, Postal \\ Code 541 24, Thessaloniki
}

\begin{abstract}
Energy efficiency and energy preservation are two primary worldwide concerns in current reality. Thus, sustainability encompasses those two issues, giving that as a general term refers to the capacity to endure. In architecture sustainability describes environmentally conscious design techniques, minimizing negative environmental impact and enhancing efficiency in the use of materials, energy and space. In every level of design and construction of a building, environmental issues should be taken into account. Each specific decision and choice may have consequences for the environment. Sustainability through the proper and sound use of materials is an obvious practice. Beyond that, intelligence integrated in buildings can promote energy efficiency and wider life cycle. After a brief clarification of what intelligence in buildings entitles, a series of case studies are presented in order to support the fact that in deed energy efficiency and energy preservation (in some cases energy production as well) are achieved through the use of intelligent systems in structures.
\end{abstract}

Keywords: Sustainability, Building construction, Building Intelligence, Intelligent Systems

\section{INTRODUCTION}

Sustainability as a general term refers to the capacity to endure. Sustainable development is the development that meets the present needs without compromising the ability of future generations to meet their own needs (World Commission on Environment and Development, 1987). In architecture sustainability describes environmentally conscious design techniques, minimizing negative environmental impact and enhancing efficiency in the use of materials, energy and space. This paper analyzes building intelligence and the need for its existence to serve the goal of sustainability and energy autonomy. This building intelligence, as discussed below, can be achieved and served by the unique and innovative properties of Nanotechnology. The integration of new materials in buildings, as well as the development of special properties that the new materials grant the whole, renders buildings intelligent machines, almost as living organisms, which react and/or adapt to changes around them. These characteristics are that give buildings the ability to endure and in a more effective manner, without wasting precious resources.

\section{SUSTAINABILITY}

The term sustainability has emerged from concerns about anthropogenic changes in climate and the wasteful use of limited resources of the earth. Sustainability therefore involves the promotion of the more efficient use of natural resources, the protection of the environment and the ecosystem, and also the development of a more equitable global society (Khatib, 2009). The different dimensions and approaches of sustainability are shown in the following Venn diagram:

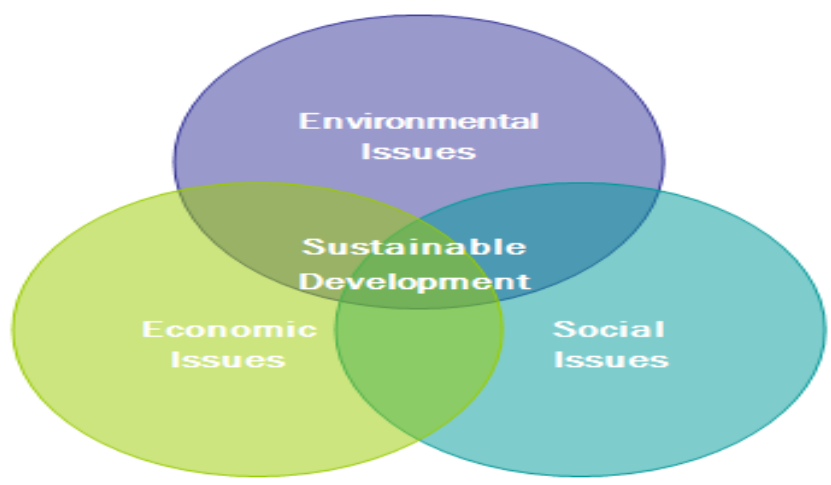

Figure 1. The different dimensions of sustainability (Khatib, 2009) 
Currently sustainability is considered as an infinite process through the ecosystem, a dynamic evolutionary way towards the improvement of management of human and natural resources. In the construction field, sustainability is a matter of grave importance. In architecture sustainability describes environmentally conscious design techniques, minimizing negative environmental impact and enhancing efficiency in the use of materials, energy and space. In every level of design and construction of a building, environmental issues should be taken into account. Each specific decision and choice may have consequences for the environment. The environment and the sustainability issues are survival issues, so it is necessary to be the primary priority. Among other competences an architect must have, the most fundamental is the effective design of buildings. The design is much more than the visual outcome, the aesthetic image of a product or a building (Szokolay, 2004). In the context of sustainability, therefore, and viability, important elements in the design process of a building are materials and energy, besides the proper selection of the location.

The stone, for instance, as a structural material is able to maintain centuries with minimal maintenance. It has excellent resistance to fire and it is not flammable nor gives off toxic fumes when exposed to extreme temperatures. Timber, as well, can be considered a renewable material. It is environmentally friendly, ubiquitous, in abundance, and through sustainable forest management can be continuously replenished, providing abundance of supply. In sustainable forests each tree collected is replaced by another, which is developed naturally or planted.

Wood has unique environmental benefits compared with other competing materials, such as concrete, aluminum, steel, plastic and glass. It is the most effective material in terms of integrated energy and environmental impacts. The log processing of trees for the reproduction of wood products requires little energy compared to other construction materials, and thus leads to minimum emission of gases and release of pollutants to the environment (Khatib, 2009). An environmentally sustainable concrete construction is one that is manufactured in a manner where the overall environmental impact over its life cycle (including its usage) is reduced to a minimum. This means that the building will be designed and completed in an ideal way for use, ie with a fixed life cycle, fixed loads, specific environmental impacts, maintenance strategies, heating needs etc. This is achieved by exploiting the intrinsic properties of concrete, such as high strength, sufficient toughness and high heat capacity. Furthermore, concrete and its components should be extracted and produced in an environmentally sound manner.

The viability of concrete as a material is affected by the cement and inert industry. The most significant impacts of cement production relate to energy usage and pollutant emissions during the production process and the use of raw materials. The energy consumption in the production of aggregates is relatively small, but the transfer from the point of production to point of use has a high energy impact. During the production of concrete, the total energy used is not important. The environmental impacts of construction are not of major importance, compared to the contribution of the other phases of the life cycle. The only case in which energy costs are not negligible is the drying of concrete (this refers only to geographical areas with high humidity). Finally, the process of demolishing the concrete structures and crushing the waste material requires energy and therefore leads to emissions. Hence, recycling or reusing crushed concrete materials can be beneficial (Khatib, 2009).

As for metals, preventing erosion and recycling should be at the forefront as a viable means to exploit the maximum benefit from the energy invested in minerals. In the construction industry the value of the metal components, which are recovered by the collapse of a structure, ensures the prospect of their recycling. The reuse is one of the most viable and established approaches for the minimization of waste. The glass used in construction can be reused. The only drawback is that it must be extracted from the construction intact, which adds delays to the demolition. Additionally, the glass can only be reused if the size and the color are suitable. A lifecycle management system (LMS) in terms of sustainability is a systematic approach to the organization and execution of all activities involved in the various phases of the design of a structure, including the design, the construction and the acceptance by the client, the inspection of the building during its use (monitoring), the maintenance, the alteration and the degradation of a structure (a full life cycle). A flexible support structure must facilitate the floor plans, the technical installations and the building services to be easily converted over the life of the building, in cases of usage alterations. The objective of the building stock analysis is to find defects in current design concepts and to define the principles for their elimination, in order to make the concrete construction sustainable (Thielen, Wiens \& Hauer, 2007). 


\section{INTELLIGENCE IN BUILDINGS}

The term "intelligence" refers to the possession of intellectual properties that provide the ability to understand and adapt. When this term is used to describe inanimate mechanisms, there should be a clarification of the use in order to avoid misunderstandings. One should always take into account the difference between "artificial intelligence" and the complex intelligence of the human brain (intellectual intelligence).

With artificial intelligence, objects acquire the ability to perform functions similar to those that characterize human behavior, mimicking the reasoning process of living beings. One of the most appropriate comparisons of biological data with intelligent buildings is the analogy of the human skin with the shell of a building. The installed sensors of a building can recognize fire or intruders in the same way that human senses recognize any danger. The case of "intelligent buildings" results from the ever increasing demands for comfort that accompany the development of complex building forms and contents, with the consequent increase in energy requirements. One of the key functions of a building is to protect residents from extreme external climatic conditions. The inability of an inert passive building to provide comfort conditions are the cause for the existence of the supporting systems developed therein. The intelligence may be used to improve the performance of the building, making it more likely to reduce the need for energy input for heating, cooling, lighting and ventilation. A combination of an automatic control and pseudo-instinctual responses to these variable conditions can contribute to improve the living conditions and the operational efficiency in terms of energy, bringing the idea of zero energy buildings closer to reality. The office building - City Place - by Owings \& Merrill Skidmore in Hartford (1984), in Connecticut (USA) is considered as the first "intelligent" building in the world. In essence it is a building, which has integrated a large number of automated support systems (fiber optic cables throughout the building connecting an integrated set of operation systems). Ultimately, this building is far from the true artificial intelligence. According to the prevailing opinion about intelligence, intelligent buildings are just "electronically enhanced" architectural forms. (Wigginton \& Harris, 2002)

The emergence of intelligent buildings in the foreground takes the architectural design on a new phase. The requirements are more and diverse, and their treatment with the aid of new materials and construction technology leads to the creation of new forms and new aesthetics. Form and function are now simple factors to a more complex technology and design equation. To this are added other factors, such as intelligent buildings, intelligent design, intelligent materials - technologies - functions.

\section{INTELLIGENT BUILDING SKINS}

Similar to the human skin structure the building envelope can be developed. A key feature of the function of the human skin that finds similar application in buildings is the heat recovery process. The building skin must provide a specific level of impermeability and efficient performance of ventilation systems. It must stay unaffected by weather conditions and for this purpose the cladding should have multiple levels of protection against ingress of water. In many cases the building envelope receives also loads (wind, earthquakes, weight of construction). Additionally, it must mitigate heat transfer between internal and external environment, so as to ensure the formation of internal comfort conditions with less energy required (Roberts \& Guariento, 2009). Generally, the thermal comfort of a room depends on many factors such as air temperature and temperature changes, the temperature radiated from the elements of the environment, the air movement, the hydrostatic pressure, the quantity of clothes people inside the building wear and the users' activity. The comfort factors such as light, sound, air quality and humidity (fresh air, condensation, absorption) can be configured with an appropriately designed building skin (Randall, 2006).

An "intelligent" glass façade can be adjusted in a dynamic way, almost as it is alive, in changing weather conditions, adjusting systems of solar control and thermal protection. The term "intelligent" shows the ability to adapt to daily or seasonally changing climatic conditions, in order to achieve a reduction in energy consumption of the building. A façade can only be called "intelligent" when natural and renewable energy sources are used, such as solar, wind or geothermal energy, to reserve the needs of the building for heating, cooling and lighting. (Compagno, 2002)

The idea of a building skin with multiple features was originally proposed by Michael Davies in 1981. He presented the idea of a multi-functional shell that would act as a device for absorption, emission, transmission, reflection and filtering at nanoscale. Following this proposal, the intelligent skin has now grown into a cover of the building which has the ability to alter the thermophysical properties, to transform from clear to opaque, to change its color and to present various optical properties. This can be accomplished either by natural elements mounted in the building skin, or at nanoscale through materials with inherently variable properties, such as chromogenic film (e.g. photochromic, electro chromic materials). The idea of introducing the concept of variability in the material itself offers huge advantages. (Wigginton \& Harris, 2002) 
Some examples of intelligence in buildings are presented below. The capacity for adaptation and flexibility of the reactions to changing environmental conditions are briefly analyzed. The sole purpose of this reactionary behavior is for the building to retain inside the comfort conditions that were prescribed for it in advance (design).

\section{CASE STUDIES}
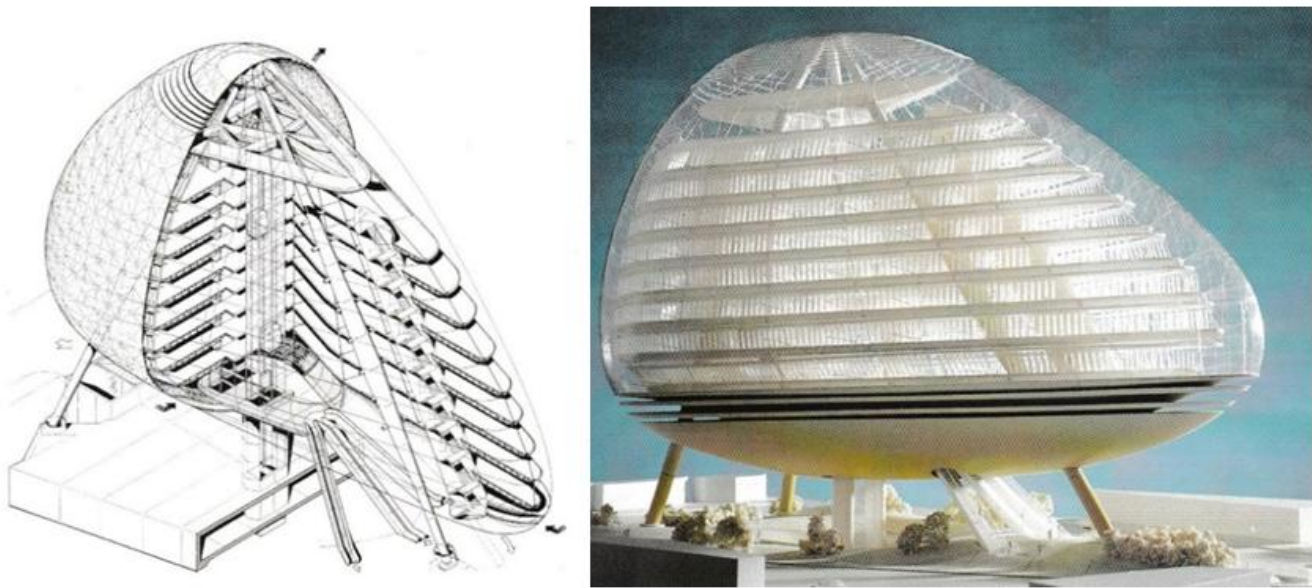

Figure 2. The "Green Building” project 1990 (Compagno, 2002).
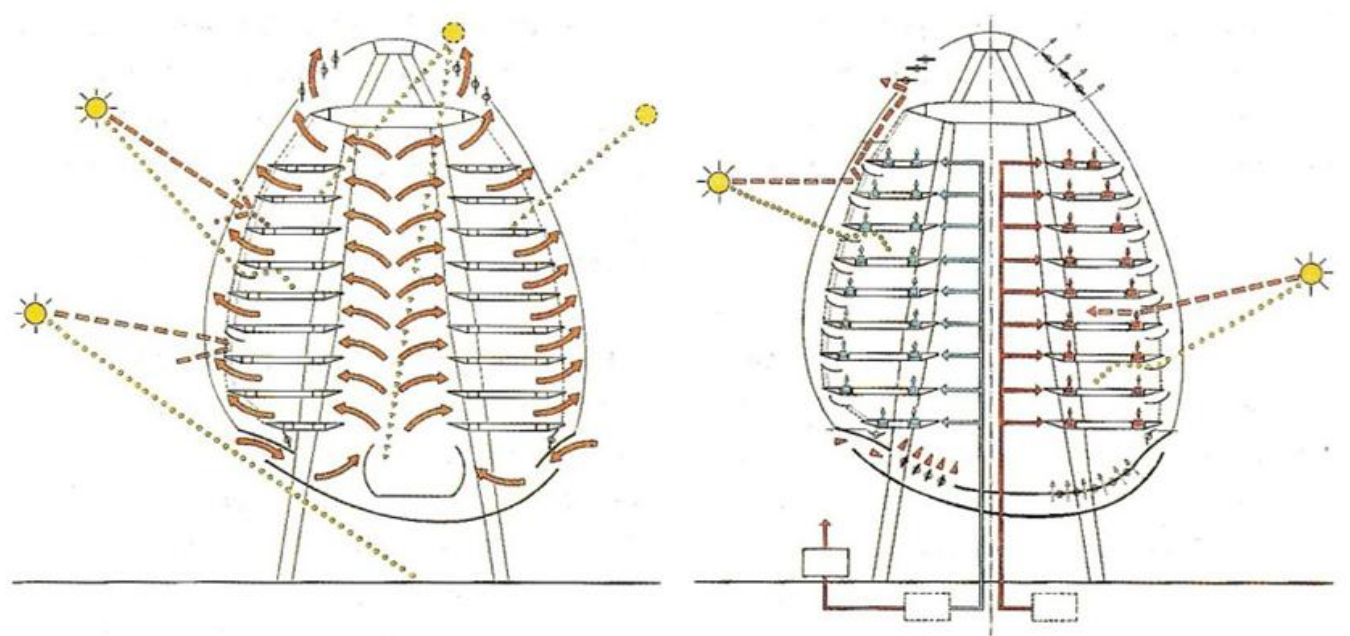

Figure 3. Schematic sections that show the airflow: warm air rises into the gap of the façade and exits through vents at the top of the building. This drops the pressure from the vacuum of the façade, which then draws fresh air into the atrium (left). Heating and cooling are provided via separate water return system (right) (Compagno,

2002).

The "Green Building": this research project (Jan Kaplicky, Amanda Levete, Tom Baker, Andy Sedgwick, Mike Beaven, 1990) represents a first attempt to reduce artificial ventilation and replace it with natural methods. The bearing structure consists of a form of tripod, where the floor slabs are suspended from. Although the double-skin façade offers protection from noise and exhaust fumes, it was originally formed in order to allow natural ventilation. The air elevates in the patio, if heated by the radiation of space, and as it rises, fresh air enters through vents in the lower parts of the building. At the same time, hot air elevates inside the gap of the façade and leaves through openings on the roof of the building. As a result of this process, negative pressure is caused inside the gap of the façade and, when windows are opened, air is drawn through the atrium, providing natural ventilation. In colder seasons, the outdoor air, which is drawn from the lower part, is preheated by the thermal energy recovered by evaporative air. The solar control and protection from glare are regulated by independently adjustable blinds. The floor slabs, which act as thermal storage, absorb the extra heat during the day and cool down by natural ventilation at night. (Compagno, 2002) 


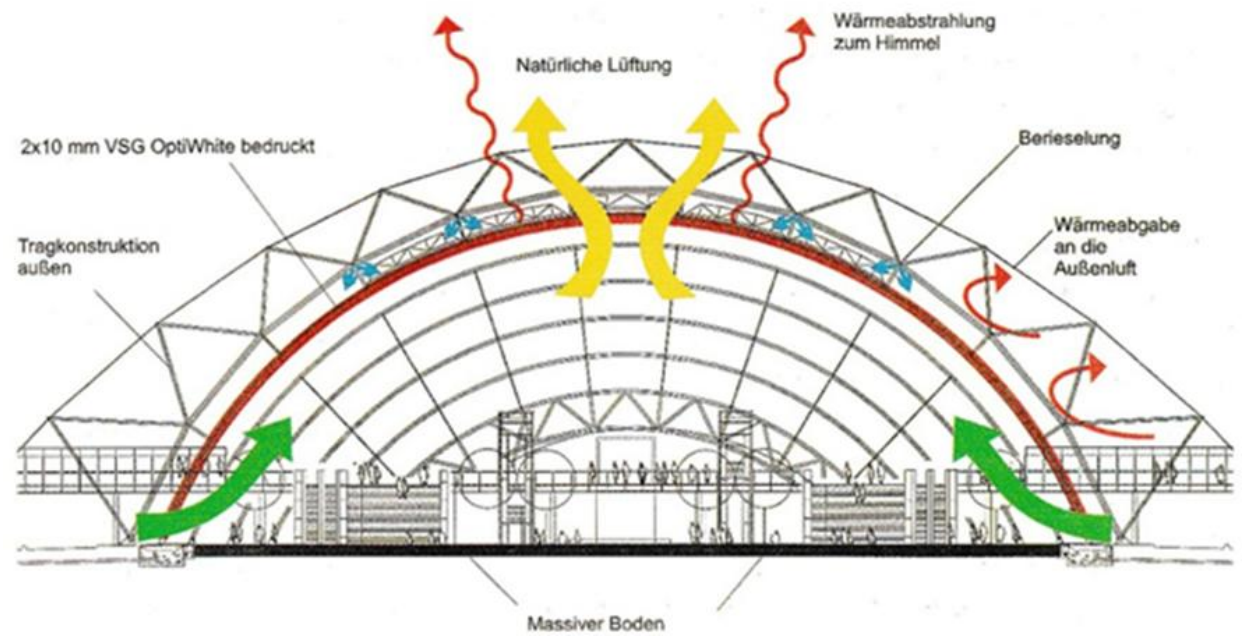

Figure 4. The main entrance hall at the New Trade Fair Center in Leipzig, 1996. The room is ventilated naturally through regulated openings at the base and the top of the glass dome. A white, reflective surface is used to control the sunlight (Compagno, 2002).
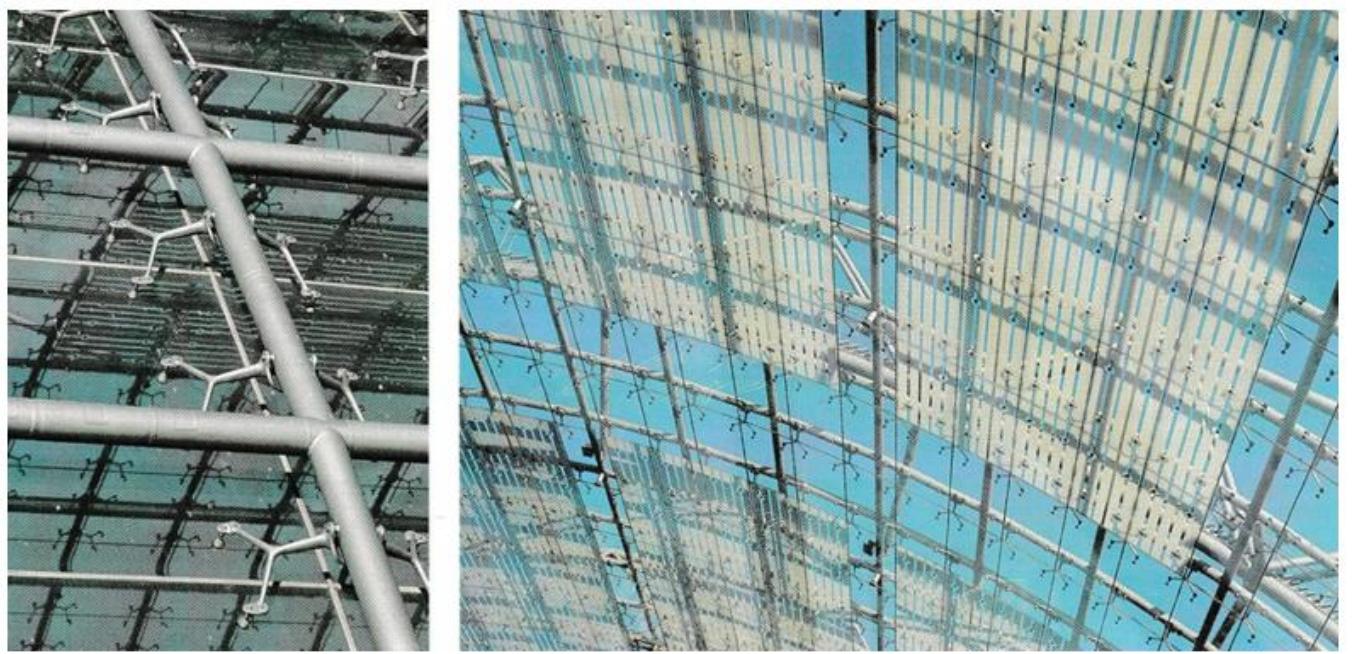

Figure 5. The glass panels are suspended by articulated support points. On the south elevation and the perimeter of the roof, the panels have a white, reflective coating that serves controlling the incoming light (Compagno, 2002)

The main entrance hall at the New Trade Fair Center in Leipzig (Gerkan Marg \& Partners, Ian Ritchie Architects, 1996) is an example of an environmentally friendly building with a single shell. The vaulted glass roof creates a space, which is protected from weather conditions, controls climate and serves as a reception, information center and distribution point of the exhibition halls. The glass hall $(250 \mathrm{~m}$ length, $80 \mathrm{~m}$ width, $30 \mathrm{~m}$ height $)$ is a structure of an elaborate metal truss with transparent glass panels in the inner side. The frame consists of ten connected arcs, and below it a vaulted metal trellis is mounted. Glass is suspended from the lattice through stainless steel links. Natural greenhouse effect generates comfort conditions throughout the year without the need for additional measures. Only during the winter further heating (through floor system) is needed to increase inner temperature by 8 degrees. Natural ventilation is achieved by openings at the base of the glass dome. Due to the geometry of the dome, airflow is generated even when there is no wind in the external environment. Office Building in Garston, Hertfordshire, United Kingdom (1994-1996, Feilden Clegg Architects) - AKA the environmental building: The new Environmental Building at Garston has been built as a demonstration building for the Energy Efficient Office of the Future (EoF) performance specifications, drawn up by a number of companies representing the manufacturers, designers and installers of building components and the fuel utilities. The building was intended to be an exemplary application of high-tech environmental design. The constructed building was announced by the government as a "prime example of British innovation" and was acclaimed as a "Millennium Product". 


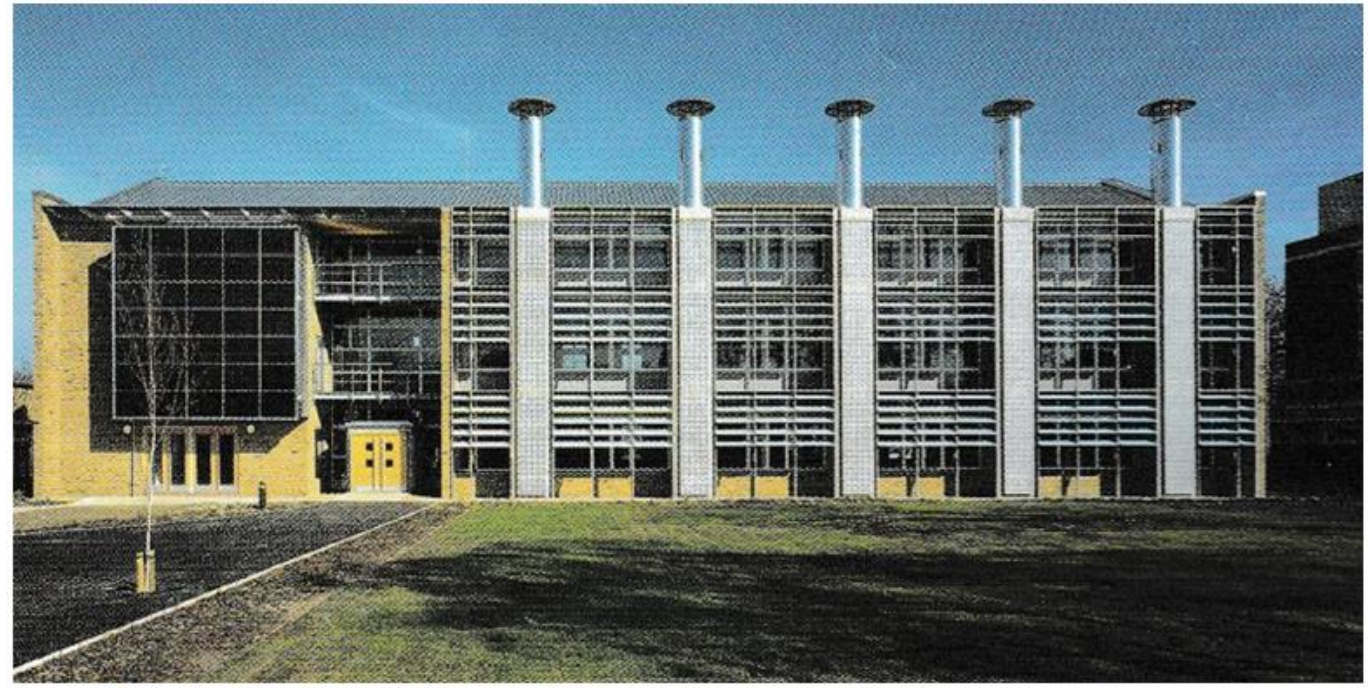

Figure 6. The façade of the environmental building (Wigginton, Harris, 2002)

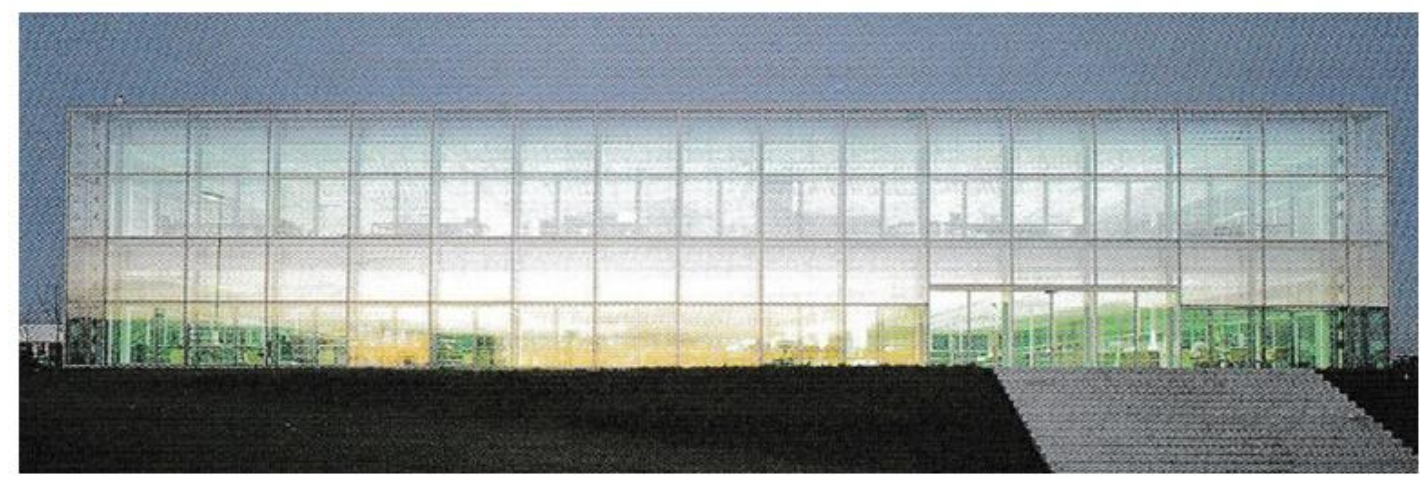

Figure 7. The façade of the Götz building (Wigginton, Harris, 2002)

The most striking feature of the building when seen from the south side is the five distinctive ventilation shafts running up the façade. These form a key part of the energy-saving natural ventilation and cooling system. Working rather like a greenhouse, the summer sun shines into the glass-fronted shafts, warming the air inside. This warmed air naturally rises out of the stainless steel 'chimneys' and causes air from inside the building to be drawn through to replace it. On a breezy day the movement of air across the tops of these chimneys increases this 'stack' effect. On very warm, still days, low-energy fans in the tops of the stacks can be turned on to give greater airflow. To make maximum use of available daylight the building has a large glass area, carefully optimized to provide high light levels but low heat losses and solar gain. To prevent excessive heating and glare from the sun shining in the building has a system of Colt motorized glass louvres on the south façade to control the daylight levels (BRE, 2000). Finally, a sophisticated building management system controls the heating, the ventilation and the cooling system to achieve optimal conditions (thermal comfort conditions). Götz - Headquarters in Würzburg, Germany (1993-1995, Webler-Geissler
Architects): the Götz building is the headquarters of a curtain-wall cladding systems manufacturer. The new building houses the departments of the company related to sales, management and design, in an open and bright two-storey pavilion of metal and glass.

The fully glazed double façade is the keystone of the energy concept of the building, controlling the air circulation in the building, optimizing the lighting conditions in the building's interior and making a considerable contribution to the usage of solar energy. The double façade is comprised of two layers of double-glazing separated by a gap of $600 \mathrm{~mm}$. Sets of openings at the ground and at the roof level of the façade and enable outside air to circulate within the gap. The amount of the air is controlled by automatically adjustable flaps. For ventilation purposes, sliding doors and high-level windows on the inner skin may be opened manually as required. (Baird, 2001) Fans situated in the corners of the cavity switch on to redistribute the warm air from the sunny to shaded faces of the building. 250 sensors monitor a wide range of conditions measured throughout the interior, and also outside the building, and a computer compares these, using fuzzy logic and neural network systems, with past situations and 
the responses then made which are stored in its memory. Occupancy sensors in workplaces activate artificial lighting. Daylight collectors monitor the progress of the sun and supply a heat pump, which provides heating and cooling, while additional cooling can be effected with nocturnal ventilation activated by ventilation flaps, sliding internal windows and removable roof. (The Architectural League of New York, 2000) Heliotrope ${ }^{\circledR}$ - The Rotatable Solar House, Freiburg, Germany (1994, Prof Rolf Disch, Architect): The cylindrical building has on one side triple-paned thermal insulated glass (U-value 0.5) and is on the other side highly thermally insulated (U-value 0.12). Exposed to the sun with the open front's special windows, the maximum possible energy and light is let into the home. Reverse for the hot summer days, the house will turn its insulated backside to the sun, to keep the home comfortably cool. And in addition, the optimization of ecological technology comes into the works with solar heat, earth-to-air heat exchangers, a wood pellet oven, ventilation with heat recovery, and low temperature radiant ceiling and floor heating. The collected rainwater is automatically filtered and reused. On the roof of the Heliotrope you will find a large mounted photovoltaic unit. Additionally affixed as balcony railings are vacuum-solar thermal collectors, which yield high energy gains for hot water and heating. The mounting system and rotation mechanism of the Sun Sail were completely newly developed: the panel tracks the sun throughout the day automatically and computer controlled - turning independently from the building itself - and additionally it pivots in steep and flat angled positions. (Rolf Disch , 2009) It is obvious that this building is not only harvesting sunlight for energy use and gain, it also preserves resources and it doesn't make use of environmentally harmful chemicals.

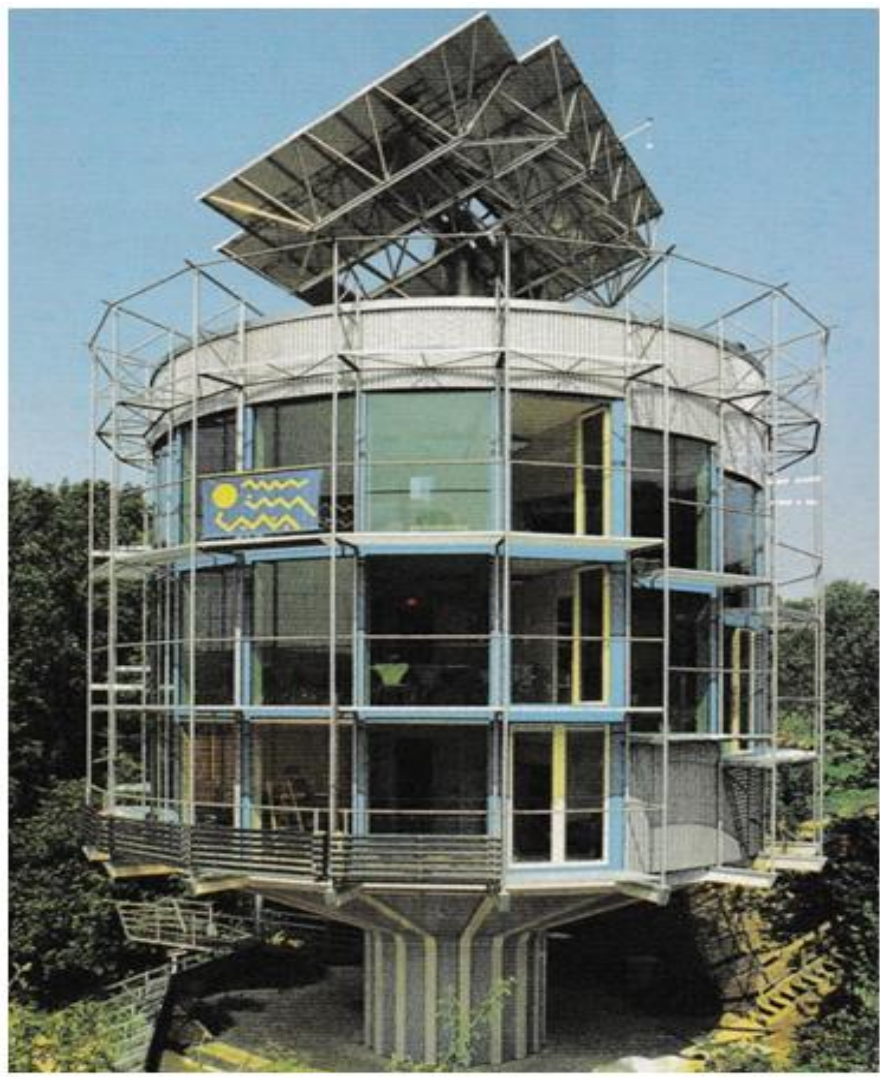

Figure 8. The Heliotrop ${ }^{\circledR}$ building (Wigginton, Harris, 2002)

SUVA House, Extension and Alteration of an Apartment and Office Building in Basel, Switzerland (1988-1993, Herzog \& die Meuron Architekten): There were two options for enlarging the SUVA Basel branch: demolition of the existing 1950 's building to give way for an entirely new building or an addition making use of the corner site. The retention of the old building gave rise to the solution of a glass enclosure covering both new (offices and apartments) and old building. The glass enclosure unites old and new into an acute corner building giving it a coherent urban presence. At the same time, the transparency and operation of the glass panels reveal the configuration as a conglomerate of two volumes. (Herzog, DeMeuron, 2010) The new outer shell consists of a triple series 
of windows -glass panels in frames of aluminumcontrolled by a computer. The upper row has prismatic panels, which are adjusted depending on the angle of the sun, the lower row has openings closed in winter and open in summer, so as to create a greenhouse effect in front of the solid component of the building, and the center row, which is located in front of the viewing windows, is opened electronically from inside. The building management system measures direct and diffuse radiation, the temperature of the facade and the wind speed. In winter the outer shell remains sealed to save energy.

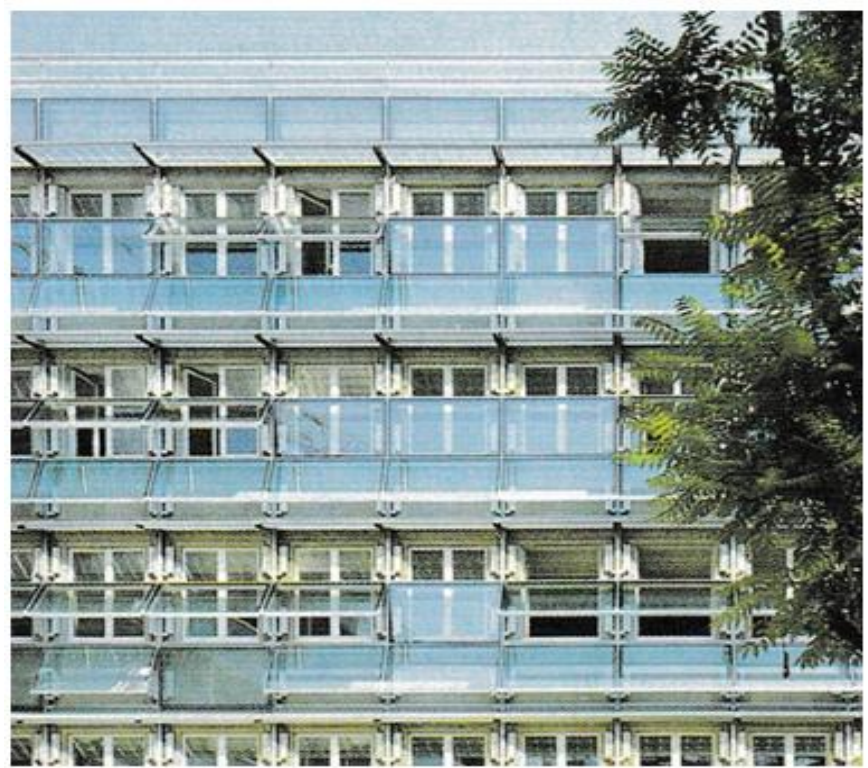

Figure 9. The front view of the SUVA house (Wigginton, Harris, 2002)

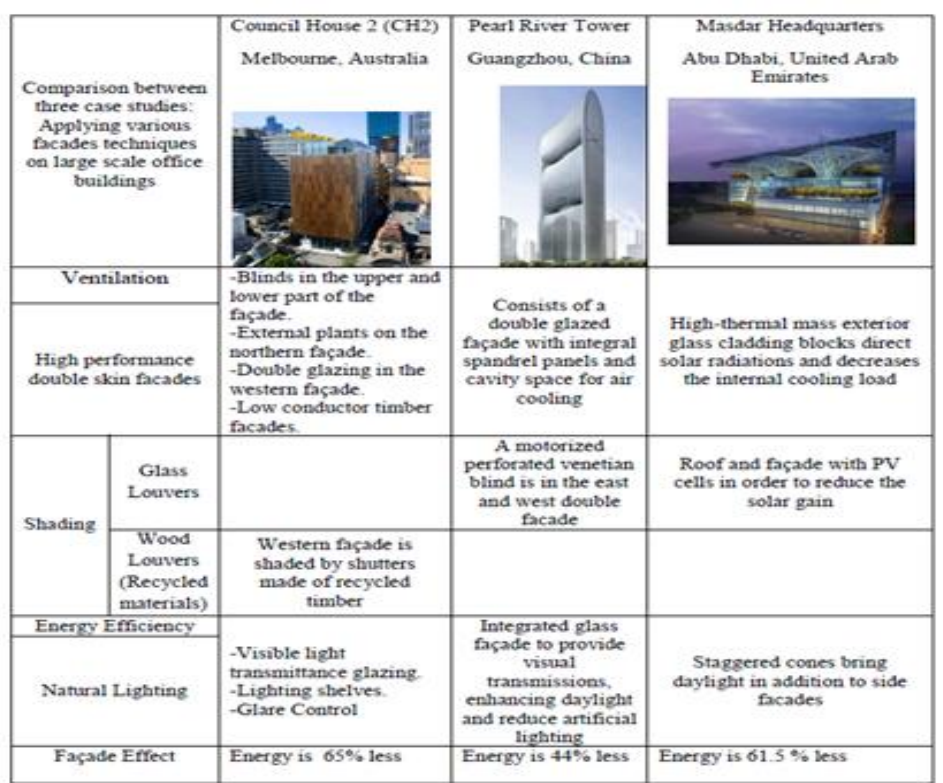

Figure 10. The comparative analysis between three buildings (Dewidar, Mahmoud, Magdy, \& Ahmed, 2010).

Likewise, the study of Dewidar, Mahmoud, Magdy, \& Ahmed, a comparison of intelligent systems integrated in three buildings, has shown the direct positive effect of the utilization of intelligence in builgings on energy. The comparative analysis of the three case studies is given briefly in the table shown in figure 10.

Supplementary, the following two cases presented involve the development of intelligent building skins:
Surfaces - Werner Sobek: The experimental construction R129 attempts to exploit all modern available innovative means of nanotechnology, sensor technology and general achievements of research on materials science, to design a multifunctional, energy efficient and structurally sophisticated light building envelope. The overall appearance and details of the skin reflect strong influences from the aerospace and automotive sector. 
R129 is designed to be used either by a person or a group of people, for work or occupation. The skin consists of light and transparent plastic. Carbon elements that add lateral reinforcement are embedded in the structure. The combination of different nanocoatings, such as electrochromic films, capable of switching properties in order to provide shading, and thin solar cells, offer the skin high degree of functionality. Thanks to the application of an electrochromic foil, which can be controlled electrically, the skin can be darker or made completely opaque, as a whole or in different parts. The flooring encloses under floor heating and other supporting building operating systems. (Klooster, 2009).

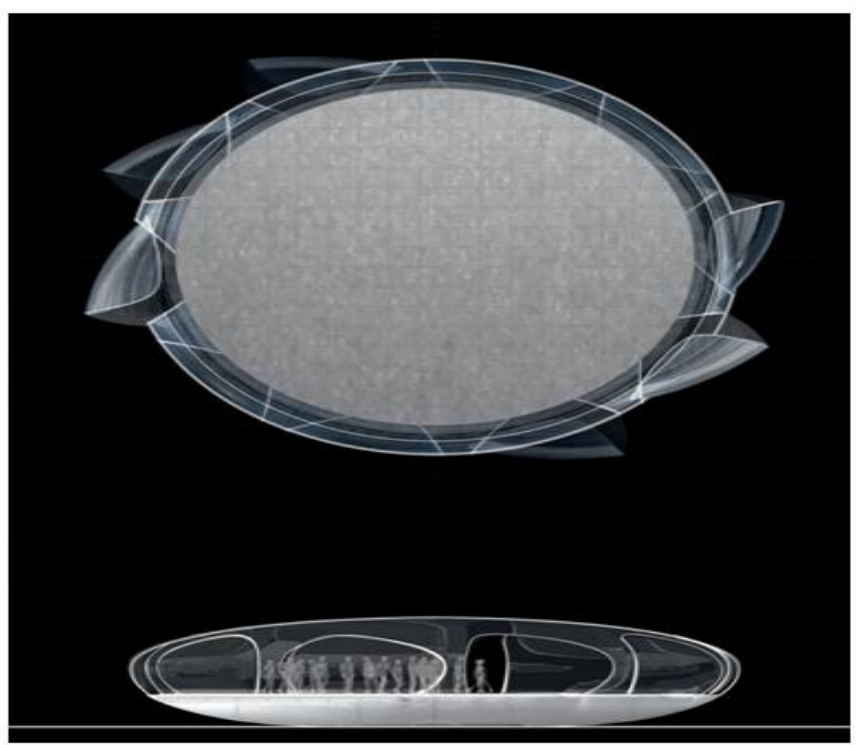

Figure 11. Floor plan and side elevation of R129 (Werner Sobek Group, 2015).

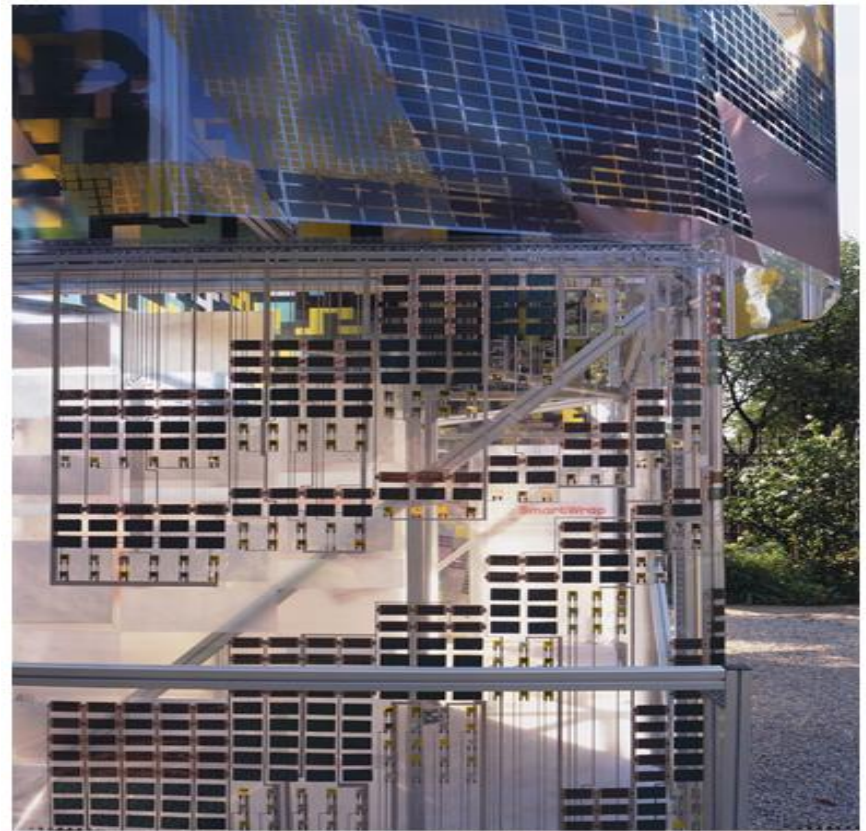

Figure 12. The original concept which incorporated innovative materials such as phase change materials, organic LEDs, organic photovoltaic cells and organic thin film transistors (Timberlake, K., 2016)

Smart WrapTM - Kieran Timberlake: The research and development of SmartWrap ${ }^{\mathrm{TM}}$ began in collaboration with industry partners, including DuPont and ILC Dover (best known for creating space suits for NASA). The concept needed to combine several technologies from various industries in order to meet the requirements of shelter, climate control, lighting, information display, and power. In 2008, the original concept for SmartWrap ${ }^{\mathrm{TM}}$ was refined and advanced through the design of Cellophane House ${ }^{\mathrm{TM}}$, a 1,800-square foot $(167 \mathrm{~m} 2)$ dwelling commissioned by The Museum of Modern 
Art. To experiment with active and passive thermal strategies, the SmartWrap ${ }^{\mathrm{TM}}$ wall assembly consisted of four functioning layers tensioned on an extruded aluminum frame. Each wall panel included an outer transparent PET weather barrier, an inner PET layer with thin-film photovoltaic cells, an inner layer of solar heat and UV blocking film, and an interior layer of PET. A vented cavity between the PET layers was designed to trap heat in the winter and vent it in the summer, reducing the amount of energy required to heat and cool the house. During the exhibition, sensors on the west facade of the house collected thermal data to provide a more complete understanding of its insulative and convective capacity. Compared to current transparent envelope systems, SmartWrap ${ }^{\mathrm{TM}}$ is designed to realize significant environmental benefits. SmartWrap ${ }^{\mathrm{TM}}$ is lightweight, resulting in a lower total embodied energy when compared to glass, and its thinness results in large surface-area coverage with a minimal volume of material relative to glass curtainwall assemblies. It can be erected in a fraction of conventional building time, with greater efficiency. At the end of its useful life, it can be easily disassembled and fed into a recycling stream (Timberlake, K., 2016).

\section{CONCLUSION}

The use of intelligent systems integrated in buildings for the control of the climate and the promotion of bioclimatic principles as well as the use of intelligent materials in building skins have a direct positive effect on the energy consumed in buildings and their overall impact on the environment. In this sense sustainability in buildings can be achieved with the integration of intelligence. Moreover, the new intelligent materials and nanoparticles can promote sustainable material usage and preservation of the natural resources of the earth. In conclusion, further research on the field of integrated intelligent systems and intelligent materials is needed in order to enhance and establish them as a common practice in the building industry.

\section{Acknowledgements}

This paper is a small part of a dissertation research which is in progress under the supervision of the following advisory committee: M. Malindretos, Professor AUTh (School of Architecture), N. Kalogirou, Professor AUTh (School of Architecture), S. Logthetidis, Professor AUTh (School of Physics). The current study is done under the support of: "IKY FELLOWSHIPS OF EXCELLENCE FOR POSTGRADUATE STUDIES IN GREECE SIEMENS PROGRAM"

\section{REFERENCES}

[1]. Baird, G. (2001). The Architectural Expression of Environmental Control Systems. London and New York: Spon Press.Brock, L. (2005). Designing the Exterior Wall: An Architectural Guide to the Vertical Envelope. Hoboken, NJ: Wiley \& Sons Inc.

[2]. Bullivant, L. (2006). Responsive Environments - Architecture, Art and Design. New York: V\&A Publications.

[3]. Compagno, A. (2002). Intelligent Glass Facades. Basel, Switzerland: Birkhauser.

[4]. Drake, S. (2009). The Elements of Architecture - Principles of Environmental Performance in Buildings. New York: Earthscan.

[5]. Drexler, H., \& S.el, K. (2012). Sustainable by Design: Methods for Holistic Housing, Basics, Strategies, Projects. Basel: Birkhäuser.

[6]. Hausladen, G., Saldanha, M., \& Liedl, P. (2008). Climateskin: Building-skin Concepts that can do More with Less Energy. Basel: Birkhäuser.

[7]. Khatib, J. (2009). Sustainability of Construction Materials. Cambridge: Woodhead Publishing Limited.

[8]. Klooster, T. (2009). Smart Surfaces. Basel: Birkhäuser.

[9]. Oesterle, E., Lieb, R., Lutz, M., \& Heusler, W. (2001). Double-Skin Facades - Integrated Planning. Munich: Prestel.

[10]. Randall, T. (2006). Environmental Design - an Introduction for Architects and Engineers. New York: Taylor \& Francis.

[11]. Roberts, S., \& Guariento, N. (2009). Building Integrated Photovoltaics - A Handbook. Basel: Birkhauser.

[12]. Szokolay, S. (2004). Introduction to Architectural Science - The basics of Sustainable Design. Oxford: Architectural Press.

[13]. Thielen, G., Wiens, U., \& Hauer, B. (2007). Sustainable Building with Concrete - a Holistic Approach along the Life-Cycle. In C. Grosse (Ed.), Advances in Construction Materials (pp. 683-690). Berlin: Springer.

[14]. Watson, D., \& Lals, K. (1983). Climatic Design: Energy-efficient Building Principles and Practice. New York: McGraw-Hill .

[15]. Wigginton, M., \& Harris, J. (2002). Intelligent Skins. Oxford: Architectural Press.

[16]. World Commission on Environment and Development. (1987). Our Common Future. Oxford: Oxford University Press.

[17]. Yu, M. (2014). Skins, Envelopes and Enclosures. New York: Routledge. 
[18]. BRE. (2000). The Environmental Building. Retrieved 2015, from BRE Projects: http://projects.bre.co.uk/envbuild/

[19]. Herzog, DeMeuron. (2010). SUVA House, Apartment and Office Building. Retrieved 2016, from Herzogdemeuron.com: https://www.herzogdemeuron.com/index/proje cts/complete-works/026-050/050-suva-houseapartment-and-office-building.html

[20]. Rolf Disch . (2009). Rolf Disch Solar Architektur . Retrieved 2015, from Rolf Disch: http://www.rolfdisch.de/index.php?p=home\&p id $=78 \& \mathrm{~L}=1 \&$ host $=2 \#$ a566

[21]. The Architectural League of New York. (2000). Gotz Headquarters. Retrieved 2015, from Ten Shades of Green: http://www.tenshadesofgreen.org/gotz.html

[22]. Timberlake, K. (2016). SmartWrapTM. Retrieved from Kieran Timberlake: http://kierantimberlake.com/pages/view/28

[23]. Werner Sobek Group. (2015). Projects - R129. Retrieved 2015, from Werner Sobek: http://www.wernersobek.de/en/projects/materi $\mathrm{al} / \mathrm{specials/r129/}$ 